\title{
Influence of Shell Number on Loading Capacity of Microcapsules Containing Fragrance
}

\author{
A. K. Aldred, W. Chokbundit, and K. Saengsorn
}

\begin{abstract}
Microcapsules of single-shell melamine-formaldehyde (MF) and double-shell urea-formaldehyde/melamine -formaldehyde (UF/MF) microcapsules loading with fragrance of varied concentrations were prepared using in situ polymerization. The microcapsules were analyzed using Scanning electron microscope (SEM) and Fourier transform infrared spectrometer (FT-IR). Loading capacity of fragrance in the microcapsules in term of percent weight of fragrance was determined using soxhlet extraction. From SEM images, shapes and sizes of single shell MF microcapsules were different depending on concentrations of fragrance and SDS added in the preparation procedure. FT-IR spectra of double-shell UF/MF microcapsules loaded fragrance presented absorption band of $\mathrm{C}=\mathrm{O}$ at $1674 \mathrm{~cm}^{-1}$ as found in that of fragrance. Percent weight of fragrance in single-shell UF and double-shell UF/MF microcapsules substantially increased with increased concentration of fragrance. Additionally, loading capacity of fragrance in double-shell UF/MF microcapsules were higher than those in single-shell MF microcapsules at the same concentration of fragrance. This would lead to higher prolongation of fragrance release from double-shell UF/MF microcapsules than single-shell MF microcapsules and fulfill the end use applications.
\end{abstract}

Index Terms-Fragrance, loading capacity, melamineformaldehyde, microcapsules, urea-formaldehyde.

\section{INTRODUCTION}

Microencapsulation of active ingredients is an attractive way to create functional products. Their stability, storage as well as degradation protection are benefits to fulfill the appropriate applications. Microcapsules containing fragrance have been adopted to produce sensational-durable materials and used in wide ranges of application such as food, agriculture, papers, textiles, medical and consumer products. Stabilization and protection of the core ingredients using porous polymer shell are its advantage of microencapsulation technique for ingredient delivery and long lasting release. Encapsulation of active ingredients, including flavors in polymer shell of urea-formaldehyde [1]-[4] and melamine-formaldehyde has been versatile [5]-[8]. Control of fragrance diffusion by barrier system of various types has been employed in fragrance prolongation, for instance, cyclodextrin host [9]-[10], solid-lipid nanoparticles [11], amphiphilic-crosslinked polymer network [12], double emulsion system [13], synthetic polymers formed by miniemulsion polymerization [14], coacervation with various

Manuscript received October 18, 2017; revised December 5, 2017.

A. K. Aldred, W. Chokbundit, and K. Saengsorn are with Maejo University, Faculty of Science, ChiangMai Thailand 50290 (e-mail: arunee.k@mju.ac.th, wijittra260@hotmail.com, saengsorn23@hotmail. co.th). carbohydrates [15]-[17], polymer blends [18] and multilayer microcapsules [19]. However, increasing in capacity of fragrance in urea-formaldehyde and melamine-formaldehyde is necessary to prolong the release period.

To increase loading capacity of fragrance, microcapsules of increased shell number using in situ polymerization was developed, in this investigation. Morphologies and chemical structures of the microcapsules loaded fragrance were analyzed using SEM and FT-IR, respectively. Percent weight of fragrance in the microcapsules was determined using soxhlet extraction.

\section{PROCEDURE}

\section{A. Materials}

Urea was supplied by BHD Prolabo, ammonium chloride was supplied by RFCL Limited, resorcinol was provided by Himedia. Hydrochloric acid and sodium dodecyl sulphate (SDS) were supplied from Merck, melamine was supplied by Aldrich. 36 \% Formaldehyde and sodium carbonate was provided by Analar, poly(vinyl alcohol) was supplied from Ajax Finechem. Acetic acid was supplied by Carlo Erba and fragrance was purchased from Honghuad.

\section{B. Preparation of Single-Shell Melamine-Formaldehyde (MF) Microcapsules}

Single-shell MF microcapsules were prepared by in situ polymerization in an $\mathrm{O} / \mathrm{W}$ emulsion emulsion using the procedure described in other literatures [4], [20]-[22]. Briefly, emulsion of $15 \mathrm{ml}$ fragrance in sodium dodecyl sulphate (SDS) solution was firstly prepared by dissolving various weights of SDS in $100 \mathrm{ml}$ of distilled water (to provide 2, 4, 5 and $6 \% \mathrm{w} / \mathrm{v}$ ) SDS. The emulsion was stirred with a magnetic stirrer at $70{ }^{\circ} \mathrm{C}$ for $1 \mathrm{hr}$. Pre-polymer of melamine and formaldehyde was subsequently prepared as follows. $2.50 \mathrm{~g}$ melamine and $4.52 \mathrm{ml}$ formaldehyde was dissolved in $100 \mathrm{ml}$ distilled water; $\mathrm{pH}$ of the solution was adjusted to 8-9 by $10 \% \mathrm{w} / \mathrm{v}$ sodium carbonate solution. Condensation reaction of melamine and formaldehyde was taken place and was carried out at $70{ }^{\circ} \mathrm{C}$ for $1 \mathrm{hr}$ under magnetic stirrer. After that, the emulsion was dropwisely added to the pre-polymer solution, $\mathrm{pH}$ of the mixture was adjusted to $4-5$ by $10 \% \mathrm{v} / \mathrm{v}$ acetic acid. $10 \mathrm{ml}$ of $0.3 \% \mathrm{w} / \mathrm{v}$ poly (vinyl alcohol) was subsequently added, the reaction was further carried out at $70{ }^{\circ} \mathrm{C}$ for $1 \mathrm{hr}$ using an overhead stirrer at a speed of $1000 \mathrm{rpm}$. Single-shell MF microcapsules were received; they were filtered under vacuum suction and then dried in a laboratory oven at $60{ }^{\circ} \mathrm{C}$ for 2 hrs. 
Another set of single-shell MF microcapsules loaded fragrance was prepared in the similar manner using various volumes of fragrance $(5,10,15,20,25,30,35$ and $40 \mathrm{ml})$ in SDS solution of $5 \% \mathrm{w} / \mathrm{v}$.

\section{Preparation of Double-Shell Urea-Formaldehyde/ Melamine-Formaldehyde (UF/MF) Microcapsules Loaded Fragrance}

Microcapsules of urea-formaldehyde (UF) were firstly prepared from urea and formaldehyde solution containing resorcinol and ammonium chloride by in situ polymerization in an $\mathrm{O} / \mathrm{W}$ emulsion as following procedure [1], [2]. Urea of $5.00 \mathrm{~g}$, ammonium chloride of $0.50 \mathrm{~g}$ and resorcinol of $0.50 \mathrm{~g}$ were weighed and dissolved in $260 \mathrm{ml}$ distilled water, respectively. $10.00 \mathrm{ml}$ of $5 \% \mathrm{w} / \mathrm{v}$ poly(vinyl alcohol) was added, $\mathrm{pH}$ of the solution was subsequently adjusted to 3.5 with $10 \% \mathrm{v} / \mathrm{v}$ hydrochloric acid. After that, $12.60 \mathrm{ml}$ of 0.06 $\mathrm{M}$ formaldehyde solution was added into the solution which was stirred at $1000 \mathrm{rpm}$ by an overhead stirrer. In situ polymerization of urea and formaldehyde was taken place and it was carried out at $55{ }^{\circ} \mathrm{C}$ for $4 \mathrm{hr}$. Urea-formaldehyde microcapsules were received; they were filtered under vacuum suction and then dried in a laboratory oven at $60{ }^{\circ} \mathrm{C}$ for 2 hrs.

Urea-formaldehyde (UF) was used as microcapsules inner layer for the preparation of double-shell microcapsules. The outer layer of double-shell microcapsules was melamine-formaldehyde which was further prepared using the similar procedure mentioned above. The preparation of double-shell microcapsules shell urea-formaldehyde/ melamine-formaldehyde (UF/MF) was performed as the following procedures.

Emulsion of fragrance in SDS solution was firstly prepared by dissolving $5.00 \mathrm{~g}$ SDS in $100 \mathrm{ml}$ of distilled water. A series of $5,10,15,20,25,30,35$ and $40 \mathrm{ml}$ fragrance was added into SDS solution. The emulsion was stirred with a magnetic stirrer at $70{ }^{\circ} \mathrm{C}$ for $1 \mathrm{hr}$. Urea-formaldehyde microcapsules, as inner microcapsule shell were added into the emulsion of fragrance in SDS, the mixture was stirred with an overhead stirrer at a speed of $1000 \mathrm{rpm}$ for $1 \mathrm{hr}$.

Pre-polymer of melamine and formaldehyde was subsequently prepared, $2.50 \mathrm{~g}$ melamine and $4.52 \mathrm{ml}$ formaldehyde was dissolved in $100 \mathrm{ml}$ distilled water, $\mathrm{pH}$ of the solution was adjusted to 8-9 by $10 \% \mathrm{w} / \mathrm{v}$ sodium carbonate solution. Condensation reaction of melamine and formaldehyde was carried out at $70{ }^{\circ} \mathrm{C}$ for $1 \mathrm{hr}$ under magnetic stirrer. After that, the emulsion with urea-formaldehyde microcapsules was dropwisely added to the pre-polymer solution, $\mathrm{pH}$ of the mixture was adjusted to $4-5$ by $10 \% \mathrm{v} / \mathrm{v}$ acetic acid. $10 \mathrm{ml}$ of $0.3 \% \mathrm{w} / \mathrm{v}$ poly(vinyl alcohol) was subsequently added, the reaction was further carried out at $70{ }^{\circ} \mathrm{C}$ for $1 \mathrm{hr}$ using an overhead stirrer at a speed of $1000 \mathrm{rpm}$. Double-shell microcapsules of urea-formaldehyde/melamine-formaldehyde (UF/MF) were received; they were filtered under vacuum suction and then dried in a laboratory oven at $60{ }^{\circ} \mathrm{C}$ for $2 \mathrm{hrs}$.

To compare functional groups of the resultant single-shell MF and double-shell UF/MF microcapsules loaded fragrance analyzing by FT-IR, UF microcapsules and melamine/formaldehyde resin were prepared in the similar manner without loading of fragrance.

\section{Analyses of Microcapsules Containing Fragrance}

Characterization of fragrance and microcapsules were performed by means of a Fourier transform infrared spectrometer (Perkin-Elmer, USA). The samples were prepared as $\mathrm{KBr}$ disc and analyzed over wavelengths of $400-4000 \mathrm{~cm}^{-1}$. Surface morphology of the microcapsules was examined under a Scanning electron microscope (Jeol Co., Japan). The microcapsules were sprinkled onto a double sized tape, coated with gold using sputtering technique and examined under the microscope.

\section{E. Determination of Fragrance Loading Capacity}

Fragrance loading capacity in term of percent weight of fragrance was performed using soxhlet extraction as explained in another literature [1]. A known weight of microcapsules $\left(W_{c}\right)$ was placed in a known weight thimble $\left(W_{t i}\right)$. The refluxed procedure was performed in $50 \mathrm{ml}$ hexane for $1 \mathrm{hr}$ using soxhlet extraction. After draining of hexane, the thimble with extracted microcapsules was then dried in a laboratory oven and cooled down in a desiccators, the final weight of thimble was noted $\left(W_{t f}\right)$. Percent weight of fragrance was calculated using equation (1). The determination of percent weight of fragrance in microcapsules was in triplicate.

$$
\% \text { Weight of fragrance }=\frac{\left(W_{c}+W_{t i}\right)-W_{t f}}{W_{c}} \times 100
$$

\section{RESUltS AND DisCUSSION}

\section{A. Characterization of Microcapsules}

Single-shell melamine-formaldehyde microcapsules containing fragrance prepared from varied amount of SDS gave different sizes and shapes as seen in Fig. 1. When 2-5 \%w/v SDS was used, spherical microcapsules were received (Fig. 1. (a)-(c), respectively) while $6 \% \mathrm{w} / \mathrm{v}$ SDS provided rod-shape single shell melamine-formaldehyde microcapsules (Fig. 1.(d)). The results attribute to effect of concentration of SDS on shape of its micelles which was sphere when low concentration was used, but rod micelles were formed at high concentration of SDS.

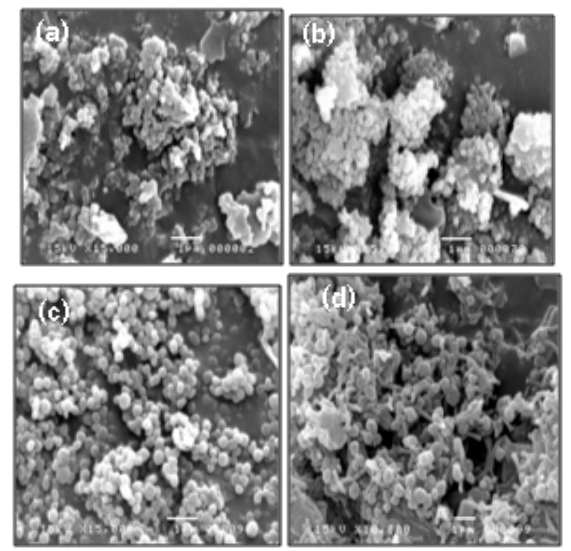

Fig. 1. Single shell melamine-formaldehyde microcapsules loaded with 15 $\mathrm{ml}$ of fragrance using (a) $2 \% \mathrm{w} / \mathrm{v}$ SDS (b) $4 \% \% \mathrm{w} / \mathrm{v}$ SDS (c) $5 \% \mathrm{w} / \mathrm{v}$ SDS and (d) $6 \% \mathrm{w} / \mathrm{v}$ SDS 
SEM images of double-shell microcapsules (UF/MF) loaded fragrance are present in Fig. 2. Shape of single shell microcapsules (UF) loaded $5 \mathrm{ml}$ of fragrance is sphere (Fig. 2 (a)), its sizes are approximately $5 \mu \mathrm{m}$. Being double-shell microcapsules (UF/MF) loaded different amounts of fragrance, they have the same size as that of single shell microcapsules (UF) (Fig. 2. (a)-(d)). However, coalescence of the microcapsules is observed when over $25 \mathrm{ml}$ of fragrance was used; the larger double-shell microcapsules (UF/MF) were observed for $40 \mathrm{ml}$ of fragrance (Fig. 2. (e)-(f)). This would affected by loss of emulsifying potential of SDS when high volumes of fragrance were used in the preparation of microcapsules.
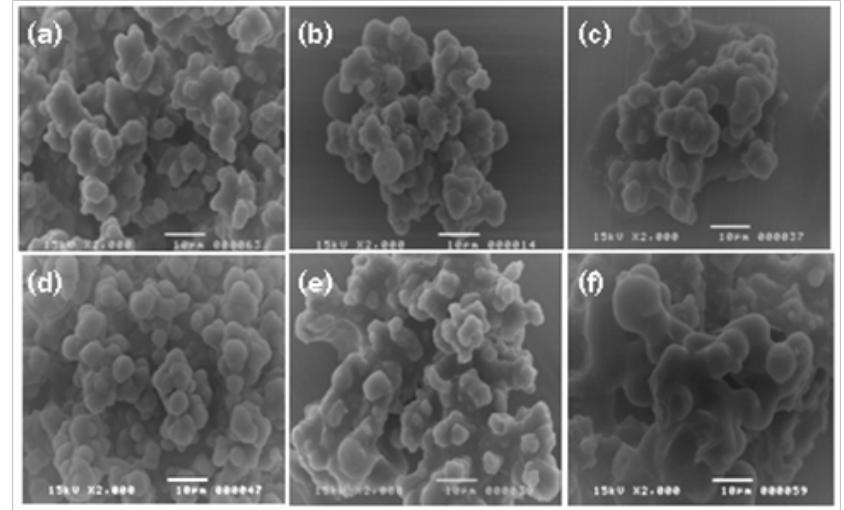

Fig. 2. (a) MF loaded with $5 \mathrm{ml}$ of fragrance (b) UF/MF loaded $5 \mathrm{ml}$ (c) $15 \mathrm{ml}$ (d) $25 \mathrm{ml}$ (e) $35 \mathrm{ml}$ and (f) $40 \mathrm{ml}$ of fragrance.

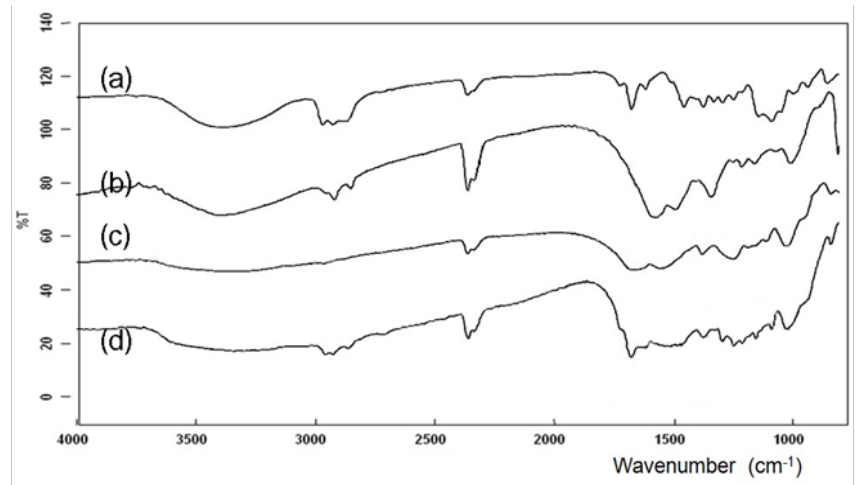

Fig. 3. FT-IR spectra of (a) fragrance (b) melamine-formal- dehyde resin (c) urea-formaldehyde microcapsules and (d) double-shell (UF/MF) microcapsules loaded with $25 \mathrm{ml}$ of fragrance.

TABLE I: PERCENT WEIGHT OF FRAGRANCE IN SINGLE-SHELL MF AND DOUBLE-SHELL UF/MF MICROCAPSULES WITH INCREASED FRAGRANCE

\begin{tabular}{ccc}
\hline \hline \multirow{2}{*}{$\begin{array}{c}\text { Vol. of fragrance } \\
(\mathrm{ml})\end{array}$} & \multicolumn{2}{c}{ Percent weight of fragrance of fragrance (\%) } \\
\cline { 2 - 3 } & MF & UF/MF \\
\hline 5 & $14.05 \pm 2.62$ & $36.82 \pm 1.07$ \\
10 & $17.35 \pm 2.53$ & $48.78 \pm 2.80$ \\
15 & $20.72 \pm 2.01$ & $44.89 \pm 1.29$ \\
20 & $24.62 \pm 2.33$ & $64.36 \pm 2.22$ \\
25 & $27.04 \pm 2.13$ & $77.16 \pm 2.61$ \\
\hline \hline
\end{tabular}

FT-IR spectrum of fragrance is shown in Fig. 3. Strong absorption band of $\mathrm{C}=\mathrm{O}$ stretching in fragrance was observed at $1678 \mathrm{~cm}^{-1}$ (Fig. 3(a)), while it is found at $1650 \mathrm{~cm}^{-1}$ for urea-formaldehyde microcapsules (Fig. 3(b)) [23] and it is absence for MF resin (Fig. 3(c)). Strong absorption band of $\mathrm{C}=\mathrm{O}$ stretching is also observed at $1678 \mathrm{~cm}^{-1}$ in FT-IR spectrum of double-shell UF/MF microcapsules loaded with
$25 \mathrm{ml}$ of fragrance (Fig. 3(d)) [24]. The result demonstrates that fragrance was trapped in double-shell UF/MF microcapsules during preparation.

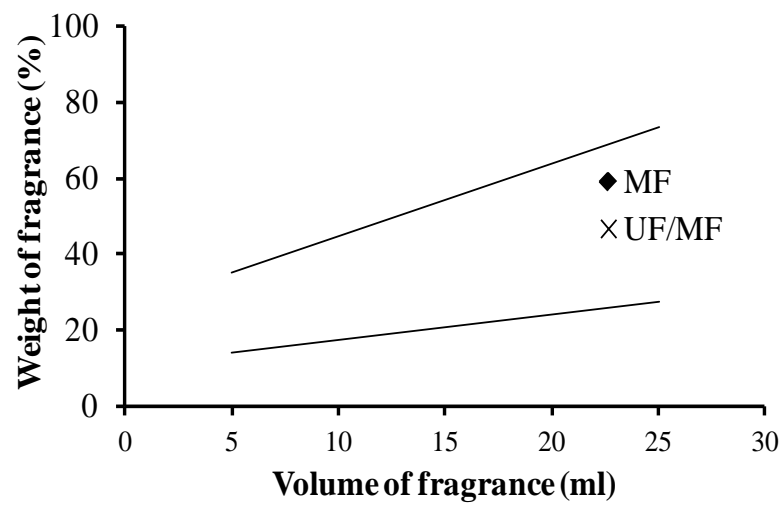

Fig. 4. Percent weight of fragrance single-shell MF and double-shell UF/MF microcapsules.

\section{B. Loading Capacity of Fragrance}

Loading capacity of fragrance in term of percent weight performed by soxhlet extraction are presented in Table I and Fig. 4. The fragrance was loaded in single-shell MF microcapsules. Percent weight of fragrance in single shell MF microcapsules found to be increased with increased fragrance volumes from 5, 10, 15, 20 to $25 \mathrm{ml}$. Increase in percent weight of fragrance with increased volumes of fragrance is also observed in double-shell UF/MF microcapsules. Additionally, the values of double-shell UF/MF microcapsules are found to be higher than those of single-shell MF microcapsules. These affected by the adsorption of fragrance by shell of microcapsules. In the preparation of double-shell UF/MF microcapsules, fragrance molecules were firstly adsorbed on surface of urea-formaldehyde shell (as inner layer). Mechanical agitation accelerated the transportation of fragrance molecules into the urea-formaldehyde shell in the second step of preparation. Fragrance molecules were subsequently encapsulated in deposited melamine-formaldehyde polymer (as the outer layer) after fragrance emulsion was added into its pre-polymer, other fragrance molecules were included in melamine-formaldehyde shell in the complete preparation procedure. Thus number of microcapsules shell has influence on loading capacity of microcapsules.

\section{CONCLUSIONS}

Single-shell MF and double-shell UF/MF microcapsules loaded fragrance were successfully prepared. SDS concentration affected to shape and size of single-shell melamine-formaldehyde microcapsules. Encapsulation of fragrance in microcapsules was indicated by the presence of $\mathrm{C}=\mathrm{O}$ absorption band at $1674 \mathrm{~cm}^{-1}$ in FT-IR spectra. The fragrance was able to be loaded in single-shell $\mathrm{MF}$ and double-shell UF/MF microcapsules. Double-shell UF/MF microcapsules showed greater percent weight of fragrance single-shell MF and they would affect to prolong release period of fragrance. Different released behaviors of fragrance from single-shell MF and double-shell UF/MF 
microcapsules will be further studied to provide helpful information for textile applications.

\section{REFERENCES}

[1] C. Suryanarayana, R. Chowdoji, and D. Kumar, "Preparation and characterization of microcapsules containing linseed oil and its used in self-healing coatings," Progress in Organic Coatings, vol. 63, pp. 72-78, 2008.

[2] E. N. Brown, M. R. Kessler, N. R. Sottos, and S. R. White, "In situ poly(urea-formaldehyde) microencapsulation of dicyclopentadiene," Journal of Microencapsulation, vol. 20, no. 6, pp. 719-730, 2003.

[3] H. Li, R. Wang, H. Hu, and W. Liu, "Surface modification of self-healing poly(urea-formaldehyde) microcapsules using silane-coupling agent," Applied Surface Science, vol. 255, pp. 1894-1900, 2008.

[4] S. J. Park, Y. S. Shin, and J. R. Lee, "Preparation and characterization of microcapsules containing lemon oil," Journal of Colloid and Interface Science, vol. 241, pp. 502-508, 2001.

[5] K. Hong and S. Park, "Melamine resin microcapsules containing fragrant oil: Synthesis and characterization," Materials Chemistry and Physics, vol. 58, pp. 128-131, 1999

[6] J. F. Su, X. Y. Wang, and H. Dong, "Influence of temperature on the deformation behaviors of melamine-formaldehyde microcapsules containing phase change material," Materials Letters, vol. 84, pp. 158-161, 2012.

[7] F. Salaun and I. Vroman, "Influence of core materials on thermal properties of melamine-formaldehyde microcapsules," European Polymer Journal, vol. 44, pp. 849-860, 2008.

[8] X. Fei, H. Zhao, B. Zhang, L. Cao, M. Yu, J. Zhou, and L. Yu, "Microencapsulation mechanism and size control of fragrance microcapsules with melamine resin shell," Colloids and Surfaces A: Physicochem. Eng. Aspects, vol. 469, pp. 300-306, 2015.

[9] C. X. Wang and S. L. Chen, "Aromachology and its application in the textile field," Fibres and Textiles in Eastern Europe, vol. 13, pp. 41-44, 2005.

[10] C. X. Wang and S. L. Chen, "Fragrance-release property of cyclodextrin inclusion compounds and their application in aromatherapy,” Journal of Industrial Textiles, vol. 34. pp. 157-166, 2005.

[11] E. B. Souto and R. H. MÜller, "Cosmetic features and applications of lipid nanoparticles $\left(\mathrm{SLN}^{\circledR}, \mathrm{NLC}^{\circledR}\right)$," International Journal of Cosmetics Science, vol. 30, pp. 157-165.

[12] G. O. Brown, C. Bergquist, P. Ferm, and K. L. Wooley, "Unusual, promoted release of quests from amphiphilic cross-linked polymer networks," Journal of the American Chemical Society, vol. 127, pp. 11238-11239, 2005.

[13] A. Edris and B. Bergnståhl, "Encapsulation of orange oil in a spray dried double emulsion,” Die Nahrung, vol. 45, pp. 133-137, 2001.

[14] K. Landfester, "Miniemulsion polymerization and the structure of polymer and hybrid nanoparticles," Angewandte Chemie-International Edition, vol. 48, pp. 4488-4508, 2009.
[15] H. C. Paula, F. M. Sombra, R. D. F. Cavalcante, F. O. Abreu, and R. C. M. De Paula, "Preparation and characterization of chitosan/cashew gum beads loaded with Lippia sidoides essential oil,” Materials Science and Engineering C, vol. 31, pp. 173-178, 2011.

[16] J. Korus, P. Tomasik, and C. Y. Lii, "Microcapsules from starch granules," Journal of Micrencapsulation, vol. 20, pp. 47-56, 2003.

[17] A. Hambleton, M. J. Fabra, F. Debeaufort, C. Dury-Brun, and A. Voilley, "Interface and aroma barrier properties of iota-carrageenan emulsion-based films used for encapsulation of active food compounds," Journal of Food Engineering, vol. 93, pp. 80-88, 2009.

[18] A. Sansukcharearnpon, S. Wanichwecharungruang, N. Leepi- patpaiboon, T. Kerdcharoen, and S. Arayachukeat, "High loading fragrance encapsulation based on a polymer-blend: Preparation and release behavior," International Journal of Pharmaceutics, vol. 391, pp. 267-273, 2010.

[19] E. Ansarifar, M. Mohebbi, F. Shahidi, and A. Koocheki, "Novel Multilayer microcapsules based on soy protein isolate fibrils and high methoxyl pectin: Production, characterization and release modeling," International Journal of Biological Macromolecules, vol. 97, pp. 761-769, 2017.

[20] H. Kage, H. Kawahara, N. Hamada, T. Kotake, and H. Ogura, "Operating conditions and microcapsules generated by in situ polymerization," Advanced Powder Technol., vol. 13, no. 3, pp. 265-285, 2002.

[21] H. Yuan, G. Li, L. Yanga, X. Yana, and D. Yanga, "Develpoment of melamine-formaldehyde resin microcapsules with low formaldehyde emission suited for seed treatment," Colloids and Surfaces B: Biointerfaces, vol. 128, pp. 149-154, 2015.

[22] J. F. Su, X. Y. Wang, and H. Dong, "Influence of temperature on the deformation behaviors of melamine-Formaldhyde microcapsules containing phase change material," Materials Letters, vol. 84, pp. 158-161, 2012.

[23] S. Chen, X. Lu, T. Wang, and Z. Zhang, "Preparation and characterization of urea-formaldehyde resin/reactive kaolinite composites," Particuology, vol. 24, pp. 203-209, 2016.

[24] Z. Qiao and J. Mao, "Multifunctional poly (melamine-urea-formaldehyde)/grapheme microcapsules with low infrared emissivity and high thermal conductivity," Materials Science \& Engineering B., vol. 226, pp. 86-93, 2017.

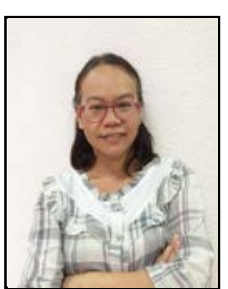

Arunee Kongdee Aldred is an associate professor at Maejo University, her $\mathrm{PhD}$ (2007) in chemistry is from University of Innsbruck.

She is interested in encapsulation of fragrance and bioactive compounds in synthetic and natural polymers for textiles and cosmetics applications. Chemical modification of polymers, textile fibers to enhance their special properties are also her interests.

Assoc. Prof. Dr. Aldred won many prizes for national and international researches and innovation competitions. 